\title{
El desarrollo urbanístico como expresión de modernidad en el género cinematográfico documental del tardofranquismo
}

\author{
FERNANDO SANZ FERRERUELA \\ Profesor Ayudante-Doctor. Departamento de Historia del Arte. Universidad de Zaragoza \\ fersanz@unizar.es \\ FRANCISCO JAVIER LÁZARO SEBASTIÁN \\ Profesor Asociado. Departamento de Historia del Arte. Universidad de Zaragoza \\ fjlazaro@unizar.es
}

\begin{abstract}
Resumen
Nuestra intención con esta comunicación es abordar algunos aspectos relacionados con el urbanismo de las ciudades españolas presentes en ciertos documentales españoles del período del tardofranquismo, especialmente, encuadrados en la década de los sesenta. En sintonía con lo que se conoce como desarrollismo económico, una de cuyas expresiones más evidentes es la fiebre constructora que se inicia en esta época, constatamos la existencia de buena cantidad de trabajos cinematográficos, realizados por productoras privadas y también por instancias oficiales, en los que esta faceta adquiere un sentido y finalidad netamente propagandísticos. Por otra parte, también nos interesa contemplar otros aspectos que tienen que ver con posiciones conservacionistas que postulan la consecución de un equilibrio entre el auge constructivo acorde con las nuevas necesidades sociales (derivadas del fenómeno de la emigración interior hacia las ciudades) y el mantenimiento de los cascos históricos, como símbolo del rico acervo cultural y espiritual del país.
\end{abstract}

Palabras clave: Cine documental; urbanismo; propaganda política; franquismo; desarrollismo.

Sumario: 1.- Introducción. 2.- Distintos tipos de urbanismo para distintos tipos de ciudad. Tratamientos en el cine documental. 3.- Las grandes urbes españolas: Madrid y Barcelona. 4.- Las ciudades de provincia: el caso de Zaragoza. 5.- Las ciudades costeras: instalaciones hosteleras y turismo. 6.- Referencias bibliográficas. 


\title{
The urban development as an expression of modernity in the tardofranquismo's documentary film genre
}

\begin{abstract}
Our intention with this communication is to approach some aspects related to the urbanism of the Spanish present cities in certain Spanish documentaries of the end of Franco's dictatorship, specially, fitted in the decade of the sixties. In tuning in with what it is known like desarrollismo economically, one of whose more evident expressions is the construction fever that begins in this epoch, we state the existence of good quantity of cinematographic works, realized by private and producers also by official instances, in which this facet acquires a net propaganda sense and purpose. On the other hand, also we are interested in contemplating other aspects that they have to see with conservationist positions that postulate the attainment of a balance between the constructive summit according to the new social needs (derivatives of the phenomenon of the interior emigration towards the cities) and the maintenance of the historical hulls, as symbol of the rich cultural and spiritual array of the country.
\end{abstract}

Key words: Desarrollismo, Documentary Cinema, Franquism, Political propaganda, Urbanism.

\section{Introducción.}

El fenómeno urbanístico y la ciudad han sido tratados bajo diversas perspectivas en distintas ocasiones en la historia del cine español, tanto en la ficción como en el género documental ${ }^{1}$, como expresión de una problemática de acuciante actualidad que afectaba a un importante contingente de la población española. Problemática, sobre todo, centrada en una vertiente concreta derivada de la adquisición de la vivienda, a pesar de que asistimos a un auge constructivo sin precedentes especialmente desde la década de los sesenta del siglo pasado. Ejemplos de todos conocidos, dentro de la ficción, fundamentándose

\footnotetext{
${ }^{1}$ No entramos a valorar la serie de filmaciones desarrolladas en el contexto vanguardista del primer tercio del siglo XX a nivel internacional (por ejemplo, Manhatta, de Paul Strand y Charles Sheeler (1920), Berlín, sinfonía de una gran ciudad, de Walter Ruttman (1927), El hombre de la cámara, de Dziga Vertov (1929) y, en el caso español, Esencia de verbena, de Ernesto Giménez Caballero (1930), por ser planteamientos que exceden a nuestras intenciones para esta comunicación.
} 
en resortes de la comedia esperpéntica con resabios neorrealistas, son El pisito, de Marco Ferreri e Isidoro M. Ferry (1959), El verdugo, de Luis García Berlanga (1963), y bajo una óptica más dura y dramática, La vida por delante, de Fernando Fernán Gómez (1958) (Torres, 2009; Lucas, 2011 y Gómez, 2011).

En otro orden de cosas, hemos de tener presente otra serie de películas -igualmente conocidas y estudiadas-, sin dejar los géneros de ficción, que profundizan en tales claves dramáticas, y que ahondan en una interpretación negativa del contexto urbano, donde se materializan toda serie de iniquidades e influencias nocivas hacia la población rural (personificación de lo incontaminado), que se instala bajo unas condiciones precarias. Estamos hablando, claro está, de filmes tan representativos como Surcos, de José Antonio Nieves Conde (1951). Por no decir de otro conjunto de cintas que reflejan bajo un sesgo desesperanzado o, en el mejor de los casos, idealmente edulcorado, el escenario de la ciudad en la España del franquismo (Sanz y Lázaro, en prensa).

En líneas generales, se trata de una visión donde dominan más los claroscuros que las apreciaciones de índole favorable, como puede deducirse por la incidencia en la vida familiar de muchos ciudadanos, más allá de los despersonalizados datos estadísticos y de los generalistas estudios sociológicos.

Por otro lado, nos enfrentamos a un panorama bastante diferente cuando hablamos de la producción cinematográfica documental, vinculada en muchas ocasiones con instituciones oficiales; por lo que, además de trasladarse el objeto de análisis y comentario al fenómeno genérico de la transformación urbanística de las ciudades, observamos un cambio substancial en el tratamiento, mucho más favorable, más aún al intentar asociar tal desarrollo con la mejora del nivel económico, $\mathrm{y}$, por ende, de vida de los españoles, situándose a la acción de gobierno como el motor de todas estas iniciativas.

Asimismo, estas actuaciones se enmarcan en un contexto mucho más complejo que tiene al Primer Plan de Estabilización Económica (1959) como hito de arranque, y que se prolongará a lo largo de la década siguiente con unos indicadores económicos en alza, y que los historiadores han bautizado con la denominación de Desarrollismo. Un contexto que no deja de manifestarse bajo constantes contradicciones, puesto que, de un lado, tenemos una progresiva liberalización económica, consecuencia de la adopción de la economía de mercado, fundamento del capitalismo occidental (tras los años de proteccionismo arancelario del 
período autárquico), pero, por otro, sigue persistiendo un cerrado inmovilismo en materia política. Una difícil dicotomía que aparece implícita en muchas producciones cinematográficas, $\mathrm{y}$, en especial, en el campo del documental, y que presenta su correlato en la confrontación de dos nociones antitéticas, tradición y modernidad, permanencia y surgimiento de ciertos valores en una época de transformación. Y todo ello orientado por un vector que cada vez se irá haciendo más significativo, el turismo (Sanz y Lázaro, en prensa).

\section{Distintos tipos de urbanismo para distintos tipos de ciudad. Tratamien- tos en el cine documental.}

En efecto, vamos a encontrar diferentes formas de abordar el desarrollo urbanístico, pero siempre bajo una pretensión propagandística, enaltecedora de la política de las instancias gubernamentales, pues no en vano, muchos de estos trabajos son patrocinados por el propio Ministerio de Vivienda (creado en 1957) y organismos afines, como tendremos la oportunidad de comentar. Estos diversos tratamientos tienen que ver con las condiciones peculiares de las ciudades y sus necesidades intrínsecas: en este sentido, en primer lugar cabe señalar la referencia a grandes urbes como Madrid o Barcelona, núcleos receptores de una gran cantidad de emigrantes procedentes del medio rural en busca de mejores oportunidades; en segundo lugar, habría que destacar otro grupo de ciudades (capitales de provincia, como por ejemplo Zaragoza) que presentan un carácter intermedio o una tercera vía, donde el patrimonio históricoartístico se erige en un atractivo turístico de primer orden, aglutinado en torno a sus cascos históricos, y en las que surge una interesante polémica al tratar de congeniar desarrollo urbanístico y construcción de nuevas viviendas con el mantenimiento de dichos centros; y por último aquellos otros cortometrajes relativos a ciudades que representan potenciales focos de atracción turística, principalmente, las emplazadas junto a la costa (lbiza, Palma de Mallorca, o algunas ciudades andaluzas etc.), en las que la principal preocupación es dotar de instalaciones, infraestructuras y servicios idóneos para los turistas -muchos de ellos de procedencia internacional- que comienzan a interesarse por ellas.

Por otro lado, el género documental, en su formato de cortometraje, la vía más habitual para canalizar estos productos, experimenta un denodado desarrollo en la década de los sesenta, entre otras razones, por la promoción puesta en 
práctica por las instituciones ligadas al mundo cinematográfico a través de sendas medidas administrativas y la instauración de premios $^{2}$ (Valle, 1962: 71 y Copeiro del Villar, 1992). En este sentido, hay que señalar también que diversos organismos oficiales, ya fueran vinculados con la industria (Instituto Nacional de Industria), la agricultura (Instituto Nacional de Colonización) o las obras públicas y la construcción (Instituto Nacional de la Vivienda), etc., iniciaron por su cuenta numerosas producciones para dar a conocer la actividad de sus sectores respectivos. Sin olvidar tampoco el surgimiento de productoras cinematográficas privadas (Hermic Films, Studio Films, Europea de Cinematografía, Leda Films, Intercine, etc.) que, al calor de las sustanciosas ayudas económicas que podían recibirse tras el trámite obligatorio de "Clasificación", por parte de la Junta de Clasificación y Censura, llevaban a cabo sus filmaciones con coste cero, y, en ocasiones, con beneficios, independientemente de su posterior rendimiento comercial en taquilla.

Un capítulo aparte merece la producción por parte del organismo oficial NO-DO (Noticiarios y Documentales Españoles), de trascendente influencia para todos los anteriores, tanto desde el punto de vista formal como significativo (Tranche y Sánchez Biosca, 2000).

\section{Las grandes urbes españolas: Madrid y Barcelona}

Respecto al primer grupo de ciudades, disponemos de ciertos ejemplos que pueden servir para comprender algunos de esos condicionantes que hemos esbozado. Empezando con la propia capital de España, Madrid, y aprovechando la conmemoración del cuarto centenario de su capitalidad en 1961, se filman varias películas que tratan de cotejar los abundantes cambios en la parcela urbanística y la decisiva transformación de su aspecto con la intención de configurar una digna imagen de centro administrativo y político del país. Así sucede en Madrid, 1561-1961, de Fernando de Madariaga (1961), en la que se hace un repaso a sus fases históricas sucesivas -un procedimiento bastante habitual en este tipo de documentales (Sanz y Lázaro, en prensa)-, para llegar al siglo XVI, con los

\footnotetext{
${ }^{2}$ Sin ir más lejos, a finales de 1961, el Sindicato Nacional del Espectáculo (dependiente de la Dirección General de Cinematografía y Teatro, y ésta del Ministerio de Información y Turismo) creó los Premios Nacionales para cortometraje.
} 
reinados de Carlos I y Felipe II. La dinastía de los Austrias, por medio de los inicios de la construcción de la Plaza Mayor y la urbanización de los descampados y arrabales del Madrid medieval, contribuye efectivamente a la definición de una condición acorde con el alcance imperial que asume el reino en aquellos tiempos. La labor de sus sucesores no llega al nivel de los anteriores, en sintonía con la visión historiográfica oficial del inicio de la decadencia política del Imperio hispano después de la muerte de Felipe II. De tal modo que solamente se refiere en el comentario (que sigue las pautas del narrador en off omnisciente, popularizado por NO-DO, una de las influencias a las que antes aludíamos) que los reyes subsiguientes intervinieron en edificios aislados, como sucede con Felipe IV, que mandó construir el Palacio del Buen Retiro, entre otros. Ya con la dinastía borbónica, en la segunda mitad del siglo XVIII, se destaca la acción de Carlos III, que llevó a cabo la más vasta obra de embellecimiento y modernización de la ciudad, con la creación de infraestructuras y construcción de nuevos edificios en torno, especialmente, a un eje principal, el Paseo del Prado. Es en este momento cuando verdaderamente, Madrid dejó de ser una aldea para convertirse en el epicentro de gobernación del mundo hispano... Ya en el siglo XIX, se pasa a mencionar a Alfonso XIII, a quien se le reconoce -de alguna manera- como el artífice del Madrid burgués, mediante la creación de vías de ensanche, bulevares arbolados y zonas verdes, así como los inicios de la construcción de la Ciudad Universitaria. El documental culmina con la mención a la intervención del gobierno de Franco en la generación de una nueva política constructiva, acorde con las necesidades primarias de habitación para la creciente población, fenómeno demográfico sin el cual -insistimos- no se entienden tales actitudes, que se emparenta con la gestión, siempre equilibrada y armónica, de un tejido de polígonos industriales que rodean a la capital. Vemos de esta manera cómo enseguida se asocia el desarrollo urbanístico-constructivo con la iniciativa de los gobernantes en cada momento histórico. Una tendencia dirigista y personalista que cristalizará en la contemporaneidad, como ya hemos comprobado.

Esta tendencia queda plenamente manifiesta en el documental Capital, Madrid, de José Luis Borau (1962), producido por el Ministerio de Vivienda. En el inicio del texto, se deja explícita la intención de exponer algunas de las circunstancias que configuran el ambiente y la vida de la gran ciudad. Su contemplación ha de mover a suscitar el interés hacia los problemas urbanisticos cuya ordenación es uno de los grandes objetivos del Plan (General de Ordenación Urbana). 
Así, en efecto, en ese mismo año 1961, se procedía a reformar el Plan General de Ordenación Urbana de la capital tras su última promulgación, en 1946. El texto oficial sería finalmente aprobado en 1964. Las líneas maestras de dicho Plan, según el Comisario de Urbanismo de Madrid, Carlos Trías Bertrán, eran la transformación del Madrid de polo de atracción en polo de impulsión de la región central, basada en la política de la descongestión, la repoblación forestal en los alrededores para limitar la expansión, la desconcentración del casco urbano mediante la creación de núcleos comerciales y dotación de servicios sociales y culturales en la periferia, el desplazamiento de la gran industria hacia las zonas de descongestión y la fluidificación del tráfico de acceso y circunvalación (Terán, 1982: 390).

Volviendo con el trabajo de Borau, tras hacer mención, desde un punto de vista declaradamente nostálgico (con la proyección de postales fotográficas), del Madrid de finales del siglo XIX, en que el tráfico rodado todavía no era un problema de primer orden, se pasa a hablar del inicio del proceso de industrialización, que conllevaba la llegada de emigrantes de otras regiones del país en busca de trabajo. La consecuencia inmediata fue el emplazamiento de barrios chabolistas en el entorno de la ciudad bajo condiciones infrahumanas de habitabilidad. El Plan de 1946, y, posteriormente, el de 1961, pretendían resolver estas carencias. A partir de los años cincuenta, en que este fenómeno demográfico es un hecho constatable, se aboga por dar respuesta a las nuevas necesidades surgidas a través de la construcción de bloques de viviendas que asumen una estética racionalista, en consonancia -así se menciona en el documental de Borau- con las nuevas formas artísticas (en las artes plásticas, la abstracción, o en la música, el jazz). La puesta en marcha de estas campañas constructivas -se afirma en el documental con planos y esquemas ilustrativos, en la línea didáctica común en este tipo de filmes- ha de descongestionar el área metropolitana, y se establecen previsiones del crecimiento demográfico de la ciudad incluso teniendo como umbral el año 2000 (Sambricio, 2004). El cortometraje se cierra teniendo como fondo musical el chotis con el que se iniciara, y con la siguiente predicción en forma de anhelo que aúna, una vez más, pasado y presente: El nuevo Madrid ha de ser una ciudad que sepa compaginar su pasado y sus tradiciones con las exigencias de nuestro tiempo ${ }^{3}$.

${ }^{3}$ Expediente de censura. (A)rchivo (G)eneral de la (A)dministración, (03) 121, Sign. 36/03938. 
De 1963 data un nuevo proyecto que tenía al traslado de la capitalidad del reino como razón de su filmación, Madrid, capital de España ${ }^{4}$, dirigido por Gustavo Pérez Puig, y producido por la Subsección de Patrimonio del Ayuntamiento de Madrid, haciendo un nuevo homenaje a la figura de su promotor, Felipe II, que trajo a la pequeña villa carpetana, la capital del mayor imperio del mundo, Madrid hubo de improvisar su aspecto de gran ciudad (...). Esta ciudad que se ensancha en nuevos barrios residenciales capaces de responder al ritmo demográfico que pasa la cifra de los dos millones de habitantes.

Podríamos citar algunos ejemplos más sobre Madrid ${ }^{5}$, pero merece la pena detenerse también en Barcelona, como sucede con Barcelona, vieja amiga ${ }^{6}$, de Jorge Grau (1961), realizado por Procusa. En este trabajo, se trata de resaltar la triple faceta de la capital catalana como centro industrial, monumental y artístico, haciendo el habitual recorrido por sus enclaves más conocidos. Si bien es cierto que, como aparece mencionado en la sinopsis y expresado en las imágenes, se ocupa más de la faceta monumental y artística que de la estrictamente urbanística, apareciendo más destacada esta materia en el documental Barcelona, nuevas viviendas ${ }^{7}$, de Ramón Sainz de la Hoya (1963), financiado por el Instituto Nacional de la Vivienda en colaboración con Filmarte, en una línea similar al film de Borau. Al final del expediente de censura se explicita que este documental en color producido para el Ministerio de la Vivienda tiene por objeto reflejar la labor del Ministerio en Barcelona y a este fin se ha dirigido todo el rodaje y comentario.

\section{Las ciudades de provincia: el caso de Zaragoza}

Zaragoza es otra ciudad que, aun no siendo de las más importantes por su tamaño y número de habitantes en el conjunto del país en este momento (encuadrable dentro del grupo de "ciudades de provincias", como entonces se decía), va a asumir un similar carácter receptor de población procedente en

${ }^{4}$ AGA, (03) 121, Sign. 36/04844.

${ }^{5}$ Como Madrid, la puerta más cordial (Javier Aguirre, 1967). AGA, (03) 121, Sign. 36/04959.

${ }^{6}$ A.G.A. (03) 121, Sign. 36/04830 y Sign. 36/03862. En esta última caja, encontramos el expediente del documental Así es Valencia, de Pascual Cervera (1962), producido igualmente por Procusa, el cual sigue los elementos constitutivos de Barcelona, vieja amiga.

${ }^{7}$ AGA, (03) 121, Sign. 36/04855. 
su mayoría de la propia región aragonesa. Igualmente localizamos sendos documentales que se ocupan de su desarrollo urbanístico asociado al económico, y, a la vez, enfatizan los atractivos turísticos basados en la riqueza patrimonial que atesora. Una de estas películas es Zaragoza, ciudad inmortal, de José Antonio Duce (1961) (Lázaro, 2006), que sigue las premisas formales y significativas de Capital, Madrid o Barcelona, vieja amiga.

Un trabajo anterior que nos sirve de precedente al de Duce, planteado en el mismo año de la promulgación del Primer Plan de Estabilización, 1959, es Zaragoza, ayer $y$ hoy ${ }^{8}$, dirigida por el realizador habitual de NO-DO, Francisco Centol, con guion del catedrático -el también aragonés- Antonio Beltrán. Se trata de un texto en el que se hace un extenso y documentado recorrido histórico y urbano por la ciudad de Zaragoza y por algunas de las principales localidades de la provincia desde sus orígenes ibéricos hasta la contemporaneidad. El paso definitivo al tiempo actual se efectúa a través de la descripción bastante optimista del desarrollo urbanístico que ha experimentado la ciudad, palpable sobre todo a partir del siglo XIX, pero concretado especialmente en las últimas décadas hasta el punto de configurar un ámbito diversificado en distintas áreas:

Un día, la gracia decimonónica del Paseo (de la Independencia), perfil y enjundia de la ciudad de nuestro tiempo, se desbordaría a través de los hierros de la verja de la puerta de Santa Engracia y crearía la delicia provinciana de la Plaza de Aragón. Más tarde se abriría la Plaza de José Antonio, nobles edificios y un barrio completo al progreso urbanístico de la vieja Caesaraugusta. Y surgen barrios y ensanches: y las avenidas de Fernando el Católico, lanzadas camino de Valencia... (...) Y así se nos presenta como capital de provincia abierta generosamente a su futuro. Militar en su Capitanía General, su Academia y su Base Aérea, jurídica en su Audiencia Territorial y sabia en su ciudad universitaria...

Por otro lado, además de la mención al desarrollo urbanístico zaragozano presente en los cortometrajes de José Antonio Duce y Francisco Centol, hallamos otro aspecto que interesa poner de relieve, y que tiene que ver con el impulso comercial e industrial, adscrito al mensaje de modernidad del que se quiere dotar a este tipo de documentales. Para ello, se va a utilizar la actividad de la Feria de Muestras,

${ }^{8}$ AGA, (03) 121, Sign. 36/04811. 
fundada en 1941, como ejemplo de tales avances. Recinto comercial que, junto al Hospital Miguel Servet y el Estadio Municipal de fútbol "La Romareda”, representaba un auténtico hito para la urbanización de esta zona de la ciudad.

Esa visión de la ciudad ofrecida por los documentales citados, en los cuales, a pesar de apostar decididamente por una imagen moderna y de desarrollo urbano de las capitales españolas, no se prescindió de las referencias a los cascos históricos, a su recuperación, saneamiento y, en su caso, reconstrucción, ha de ponerse en relación con no pocos textos de la época, en los que políticos e intelectuales reclamaban una visión conservacionista de la ciudad y su patrimonio.

Así, para el caso de Zaragoza contamos con algunos textos sumamente elocuentes, como La ciudad antigua en la ciudad moderna, publicado por el citado Antonio Beltrán en 1958, en el que, con gran visión de futuro, defiende como algo necesario la combinación del desarrollo, con la conservación y defensa de los cascos históricos y el patrimonio arquitectónico. Tarea que entraña numerosos problemas logísticos y de infraestructuras, que es necesario gestionar racionalmente, buscando el difícil equilibrio entre los requerimientos de la evolución, el saneamiento, el tráfico y la modernización urbana y las premisas impuestas por la conservación. Todo ello con un objetivo sumamente importante, que no es otro que el de tomar conciencia de que las actuaciones urbanas y en el patrimonio arquitectónico deben estar inspiradas por una noción de conjunto (Hernández, 1998: 59-76) y no por la de una suma de elementos -edificios, vías, etc.-, que carecen de sentido de forma aislada:

Nos encontramos, pues, con una situación de hecho: normalmente, las ciudades actuales del viejo mundo coinciden, en una parte mayor o menor de su superficie, con las ciudades antiguas que les dieron origen (...). Por lo tanto, no es de extrañar que la mencionada coexistencia produzca problemas que, en ocasiones, pueden llegar a la colisión de intereses de los que la vieja ciudad merece con los que la nueva ciudad postula. Si mediante la limitación a lo debido de unas y otras aspiraciones puede conseguirse la posibilidad de armonizarlos, los problemas, por difíciles que aparezcan, se resolverán. Si prevalece, irracionalmente, uno de los dos criterios y la falta de la deseada armonía se convierte en lucha, no será raro, que los intereses materiales y actuales venzan en la pugna (...). Y se cae en el error, casi siempre nefasto, de limitarse a respetar edificios aislados por razones artísticas, o más raramente por consideraciones históricas; en contadas ocasiones se valora el sentido ambiental, y aún 
menos se piensa en la respetabilidad de los conjuntos, sobre todo cuando el valor individual de sus elementos no es considerable. (Beltrán, 1958: 38-39)

En la misma línea hemos de citar el artículo publicado por Mariano Rabadán en la revista Zaragoza en 1967 (Rabadán, 1967: 58-59). En su ensayo, que parece destilar una cierta nostalgia debida a las constantes transformaciones urbanas habidas a lo largo de las últimas décadas y al deterioro que el casco histórico de Zaragoza arrastraba a aquellas alturas, reconoce la urgencia y la necesidad de emprender acciones inmediatas que contrarresten los efectos de dicha situación:

No obstante, y si bien por las razones apuntadas, unidas a las de higiene, tráfico viario y modernización ciudadana, comprendemos la necesidad de la reforma, urbanización actualizada y puesta al día de Zaragoza, de la que en estos momentos, y tal como ha quedado, poco le resta ya que recuerde su antigua fisonomía, pues los planos y trazados de sus calles no coinciden apenas con los de principios de siglo; una vez abiertas las calles de General Franco, San Vicente de Paúl, plaza del Pilar, etc. (Rabadán, 1967: 58-59)

Pese a ello, y de acuerdo a esa voluntad conservacionista, este autor advierte de que todavía se está a tiempo de rescatar de la destrucción, algunos edificios -o partes de ellos- que a su modo de ver inevitablemente han de acabar desapareciendo a causa de los embates del desarrollo urbano, proponiendo la idea -más utópica que viable- de crear una suerte de "reducto urbano" en el que aunque fuera de forma aislada y descontextualizada, se pudieran reunir dichos elementos urbanísticos, como si de un museo de la memoria arquitectónica al aire libre se tratase, de forma similar a como se había planteado en el Pueblo Español de Barcelona con motivo de la Exposición Internacional de 1929:

Creemos, no obstante, que debe respetarse, como preciadas reliquias, todo lo bueno que de lo antiguo ha llegado a conservarse hasta nuestros días, y como en el devenir de los tiempos nuevas vías y edificaciones han de reemplazar casas y patios dignos de pervivir, si no en su actual emplazamiento sí en otros lugares de la ciudad, sugerimos, ya hace un par de años, la idea de crear una zona adecuada, en un sector recoleto y céntrico, que no pueda ser afectada por las reformas urbanas que, inevitablemente, se avecinan, para trasladar alli, debidamente acondicionados y armónicamente conjuntados, puertas, balcones, rejas y ventanales, columnas, aleros. (Rabadán, 1967: 58-59) 
Para demostrar la viabilidad de su postura, Rabadán proponía los ejemplos de Madrid y Barcelona, ciudades que, a su modo de ver, habían conseguido llevar a cabo ese difícil equilibrio entre apertura y desarrollo urbano, y conservación de los cascos históricos:

Tenemos una Barcelona contemporánea y cosmopolita que ha sabido conservar, engrandecer y completar su magnífico barrio Gótico, que, rodeando la suntuosa catedral (...) a pesar de estar rodeado de calles tan modernas como la vía Layetana, paseo de Colón, Ramblas o plaza de Cataluña (...) también Madrid quiere proteger el barrio histórico de su ciudad y, junto a las trepidantes y modernizadas calles de Alcalá, Bailén o Atocha, conserva su hermosa y porticada plaza Mayor, Arco y calle de Cuchilleros, plaza de la Villa o Cava de San Miguel. (Rabadán, 1967: 58-59)

Finalmente Rabadán lleva a cabo otra singular propuesta, siendo en este caso consciente de la necesidad de dotar de actividad, humana y comercial, al casco antiguo. De una forma original, aunque desde luego bastante despegada otra vez de la realidad e inspirada por un cierto regusto de pintoresquismo nostálgico aragonés, propone la posibilidad de crear un barrio típico zaragozano. Se trataría de un nuevo reducto creado artificiosamente y como tal, necesariamente poco genuino, más allá de la adaptación a los arquetipos tradicionales de "lo aragonés", conscientemente pretendidos. Iniciativas muy de acuerdo a otras coetáneas tendentes por ejemplo -en el caso del estudioso del folclore y la indumentaria aragonesa Demetrio Galán Bergua- a configurar un modelo prototípico y uniformador de algo definido por su variedad y heterogeneidad, como es el traje regional aragonés. Rabadán propone que en este barrio debería generarse una actividad económica, que habría de encaminarse hacia el campo de la actividad turística. Un aspecto éste último particularmente reseñable, ya que Rabadán llega a romper una lanza, no tanto por el turismo exterior como por el interior, considerando su propuesta como una nueva alternativa para el ocio de los zaragozanos, basada en el consumo de productos típicos aragoneses, frente a otras modas advenedizas:

Este barrio típico zaragozano, que podría ser al mismo tiempo una exposición permanente de los productos de la ciudad y la provincia, con sus obligados moradores, industriales, comerciantes, dependientes y servidores de ambos sexos de los establecimientos citados, que deberían vestir en las horas de trabajo, desde luego con todo el decoro y propiedad que merecen, trajes ambientados con sus 
oficios y épocas, daría vida y animación a este sector de la ciudad, que, como un pequeño pueblo baturro, injertado en el corazón de la urbe, sería visitado y financiado en su entretenimiento y conservación por los expositores, empresarios explotadores de las industrias en él enclavadas, y por el público (...), no sólo los turistas forasteros, sino los propios zaragozanos, quienes, seguramente, irían a comer unas costillas de ternasco asadas a la brasa, unos pollos a la chilindrón o unas magras con tomate, regadas con vinos de la tierra, en un mesón o cocina de estilo aragonés antiguo, lo mismo que ahora van a tomar unas cervezas y salchichas a un bar de ambientación alemana o una pizza y vino, más o menos siciliano, a otro con decoración italiana. (Rabadán, 1967: 58-59)

Conceptos todos ellos en definitiva sumamente representativos de la España del desarrollismo donde se concita una verdadera amalgama ideológica, en la que conceptos como desarrollo urbano, revitalización de los cascos históricos, promoción económica, turismo, etc. van de la mano de otros mucho más conservacionistas, sobre todo en la línea de la añoranza del tiempo pasado, la defensa -a veces a ultranza- del patrimonio y el respeto, en definitiva, al pasado y a los rasgos definitorios de la idiosincrasia popular, en este caso aragonesa.

En cualquier caso, este tipo de iniciativas, tanto de opinión como cinematográficas, hay que entenderlas en un contexto en el que voces autorizadas demandaban alternativas al turismo de "sol y playa", que se había impuesto ya a nivel exterior e interior en España a esas alturas, que tanto se defendía y promocionaba en el cine y desde las instituciones y que constituía una fuentes de ingresos extraordinaria. Ante ello, otros defienden un turismo menos aparatoso y que podría definirse como turismo "de interior" o "turismo cultural", orientado no sólo al descanso y al ocio, sino con una finalidad más pedagógica, y al deleite no sólo sensorial, sino también intelectual, del paisaje, los monumentos y el rico patrimonio español. Así se desprende por ejemplo de las opiniones vertidas en 1965 por Gratiniano Nieto, que ostentaba el cargo de Director General de Bellas Artes:

Si bien es verdad que los tiempos y las costumbres cambian, y que con ello cambian también de rumbo el gusto y las exigencias de las gentes, no es menos cierto que el aumento del nivel cultural y la educación más refinada dan lugar a un aumento muy apreciable de los que viajan no sólo por mero afán de evadirse de su 
ocupación habitual y de sumergirse en el lago de sol que es España, sino que viajan también para inundar su espíritu de esa serie de emociones complejas e indefinibles que se sienten ante una obra de arte singular, ante un monumento representativo de pasadas culturas, ante una ciudad cuyas calles y caseríos son capaces de suscitar evocaciones distintas a las que en medio de la ciudad moderna se sienten, o ante un paisaje intacto, en el que la naturaleza se ha dado cita para poner el alma del espectador en situaciones que rayan en lo sublime. (Nieto, 1965: pp. 14-15)

\section{Las ciudades costeras: instalaciones hosteleras y turismo}

Por otra parte, hay que hablar de otra serie de ciudades cuyo tratamiento se orienta primordialmente a subrayar sus atractivos turísticos derivados de su emplazamiento geográfico junto a la costa. Tal es así que encontramos una extensa nómina de documentales referida al litoral andaluz y a las Islas Canarias y Baleares: por ejemplo, Granada, nieve y mar, de José Luis Román (1961), producido por Cooperativa Ibérica Cinematográfica y el Ministerio de Información y Turismo. La estructura de este trabajo es la habitual, no aportando excesivas novedades: se recurre al pasado musulmán visible en los importantísimos restos artísticos subsistentes -como elementos de atractivo cultural- para recrear un ambiente evocador, de resabios románticos, reforzado con una música de fondo de resonancias árabes. A continuación, el documental se centra en el monumento más característico de la ciudad, la Alhambra. Los últimos planos dedicados a la capital granadina se emplazan en el barrio del Albaicín, con sus casas encaladas, lo que otorga un cariz de tipismo, que es conscientemente utilizado como un elemento más de captación para los visitantes foráneos. Ello se complementa con planos de la cercana comarca de las Alpujarras, donde la arquitectura popular se fusiona convenientemente con el paisaje.

En otro orden de cosas, y pasando a contemplar una vertiente más cosmopolita, se incide en el concepto de la nieve como un reclamo decididamente turístico. Así, en efecto, se nos informa sobre la estación de esquí de Sierra Nevada, con imágenes de esquiadores en una competición. Relacionado con esto, hay que destacar la mención que siempre se hace en este tipo de documentales turísticos sobre las instalaciones hosteleras, convenientemente acondicionadas para acoger al turista visitante; de ahí que aspectos como "confort", "comodidad", etc., formen parte de las alocuciones narradas. Edifi- 
cios que suelen contemplarse de manera aislada, pero que en sí mismos son referentes inequívocos de los nuevos usos y tendencias de la arquitectura contemporánea, a la vez que se les caracteriza como elementos dinamizadores del urbanismo de las respectivas ciudades en que se implantan.

Por último, sin dejar de comentar el documental sobre Granada, se hace referencia al mar, llevando la filmación a una de las localidades costeras de la provincia, Motril, con sus playas pobladas de veraneantes tomando el sol, pero también de pescadores en sus quehaceres cotidianos.

Por todo lo dicho, se busca transmitir al espectador la existencia de un equilibrio bien resuelto entre tradición y modernidad; algo que también se quiere hacer patente en trabajos como Ibiza, de José Luis Font (1962), donde conviven las modestas casas encaladas de la arquitectura popular o los bailes tradicionales, que forman parte del acervo cultural de la isla, con los modernos hoteles de reciente construcción o la música pop que suena en el interior de los locales de diversión nocturnos.

En definitiva, el cine documental español del tardofranquismo va a ser uno de los instrumentos principales por medio de los que el Régimen buscó transmitir, a nivel nacional e internacional, una imagen de modernidad. Todo ello dentro de sus frecuentes intentos orientados hacia el reconocimiento de su labor y de su buena gestión económica -teniendo como resultado cierta prosperidad y aumento del nivel de vida-, usando como argumento, entre otros factores, la creciente actividad constructiva. Todo ello sin renunciar a la conservación de los cascos históricos de las ciudades, como seña de identidad de las mismas, frente a la uniformidad que representaba el desarrollo constructivo y urbanístico de la época.

\section{Bibliografía}

Beltrán MARTíneZ, A. (1958): "La ciudad antigua en la ciudad moderna”. Zaragoza, nº 6, Diputación Provincial de Zaragoza, Zaragoza, págs. 37-67.

COPEIRO DEL VILlar, A. (1992): Historia de la política de fomento del cine español. Filmoteca de la Generalitat Valenciana, Valencia.

GómeZ, A. (2011): "Campo e ideología en la ciudad de Surcos, de Nieves Conde”. POYATO (Coord.), Clásicos del cine rural español. Diputación de Córdoba y Ayuntamiento de Dos Torres, Córdoba, págs. 79-118. 
HERNÁNDEZ, A. (1998): “La revista Zaragoza (1955-1978), una particular visión de la historia del arte aragonés". Actas del Simposio Don José Camón Aznar y la historiografía artística de su tiempo. Boletín del Museo e Instituto "Camón Aznar", Zaragoza, no 72 , págs. 59-76.

LÁZARO, F.J. (2006): “La imagen de la ciudad de Zaragoza en la obra cinematográfica de cortometraje de José Antonio Duce: Los Sitiados y Zaragoza, Ciudad Inmortal". Boletín del Museo e Instituto Camón Aznar, no 97. Museo Camón Aznar, Zaragoza, págs. 117-146.

LUCAS, P. (2011): “Imágenes de ficción para cuentos realmente viejos. Madrid y el problema de la vivienda: El verdugo, El pisito y La vida por delante". Sesión no numerada: Revista de letras y ficción audiovisual, $\mathrm{n}^{-} 1$. Universidad Complutense, Madrid, págs. 5-26.

NiETO GaLlO, G. (1965): “Los monumentos y museos como centro de atracción turística". Estudios Turísticos, no 5, Instituto de Estudios Turísticos, Madrid, págs. 5-30.

RABADÁn PINA, M. (1967): “Cómo ve el futuro barrio típico de la Seo un amigo de Zaragoza”. Zaragoza, no 26, Diputación Provincial de Zaragoza, Zaragoza, págs. 57-87.

SAMBRICIO, C. (2004): Madrid, vivienda y urbanismo: 1900-1960. Akal, Madrid.

SANZ, F. y LÁZARO, F. J. (2012), “La imagen y simbolismo de la ciudad a través del cine: el documental turístico en la España de los cincuenta y los sesenta". Seminario Arte y ciudades: arquitecturas, arte público, cuestiones sociológicas e iconográficas. Departamento de Historia del Arte de la Universidad de Zaragoza, del 4 al 6 de octubre de 2012 (en prensa).

TERÁN, F. de (1982): Planeamiento urbano en la España contemporánea (1900/1980). Alianza, Universidad Madrid.

TORRES, G. (2009): "Imágenes fílmicas de la España del franquismo". Anales de Literatura Española, № 21. Universidad de Alicante, Alicante, págs. 189-212.

TRANCHE, R. y SÁNCHEZ, V. (2000): NO-DO. El tiempo y la memoria. Cátedra y Filmoteca Española, Madrid.

VALLE, R. (1962): Anuario Español de Cinematografía 1955-1962. Sindicato Nacional del Espectáculo, Madrid. 